\title{
QUALIDADE DA SEMENTE E SENESCÊNCIA DE GENÓTIPOS DE SOJA SOB DOIS NÍVEIS DE INFESTAÇÃO DE PERCEVEJOS (PENTATOMIDAE)1
}

\author{
PAULO ROGÉRIO LUSTOSA², JOSÉ COLA ZANUNCIO ${ }^{3}$, \\ GERMANO LEÃO DEMOLIN LEITE ${ }^{2}$ e MARCELO PICANÇO ${ }^{4}$
}

\begin{abstract}
RESUMO - Este trabalho objetivou estudar a resistência de duas linhagens de soja, do programa de melhoramento do sabor da Universidade Federal de Viçosa, MG, cultivadas sob dois níveis de infestação de percevejos, em comparação com três cultivares de soja. Os genótipos estudados foram: CR-1, CR-3, Cristalina (linhagem paterna), Davis (padrão de suscetibilidade) e IAC-100 (padrão de resistência). CR-1, CR-3, Davis e Cristalina, sob baixa infestação, produziram porcentagens de sementes normais semelhantes entre si (57\%), e inferiores às de IAC-100 (77\%). Sob alta infestação, CR-1, CR-3 e Cristalina produziram percentagens de sementes normais semelhantes entre si (22\%) e inferiores às de Davis (43\%) e IAC-100 (59\%). Todos os genótipos apresentaram baixo grau de retenção foliar (menos que 6\%) quando cultivados sob baixa infestação, mas sob alta infestação, a CR-1 e IAC-100 apresentaram menores porcentagens de retenção foliar (menos que 5\%), seguida por Davis e CR-3 (6-20\%) e Cristalina (21-40\%). CR-1, IAC-100 e Davis não apresentaram plantas com caule verde sob baixa infestação, ao contrário do que foi registrado com CR-3 $(3,6 \%)$ e Cristalina $(11 \%)$. IAC-100, CR-1 e Davis apresentaram menores porcentagens de plantas com caule verde $(6,4,10,3$ e $18,3 \%$, respectivamente) que CR-3 (64,8\%) e Cristalina (77,3\%).
\end{abstract}

Termos para indexação: Glycine max, resistência de plantas, sabor da soja, , IAC-100, Davis, Cristalina.

\section{QUALITY OF SEEDS AND SENESCENCE OF SOYBEAN GENOTYPES UNDER TWO LEVELS OF BUGS INFESTATION (PENTATOMIDAE)}

\begin{abstract}
The objective of this research was to evaluate the genotypes CR-1 and CR-3, from the genetic improvement program of soybean flavor of the Federal University of Viçosa, in Viçosa, MG, Brazil, under two levels of Heteroptera infestation. The genotypes tested were CR-1, CR-3, Cristalina, Davis (susceptible genotype) and IAC-100 (resistant genotype). The genotypes CR-1, CR-3, Davis and Cristalina under low level of infestation (2.8 Heteroptera/beating) produced similar percentage of normal seeds $(57 \%)$ but inferior to the genotype IAC-100 (77\%). Under high level of infestation (6.42 Heteroptera/beating), the genotypes CR-1, CR-3 and Cristalina produced similar percentage of normal seeds but inferior to the genotypes Davis (43\%) and IAC-100 (59\%). All genotypes showed low level of leaves retention (less than 6\%) when cultivated under low level of infestation by Heteroptera but under high level of infestation of these bugs, the genotypes CR-1 and IAC-100 showed smallest level of leaf retention (less than 5\%) followed by Davis and CR-3 (6-20\%) and Cristalina (21-40\%). The genotypes CR-1, IAC-100 and Davis showed no green stem under low infestation, contrary to what was registered for CR-3 (3.6\% green stem) and Cristalina (11\% green stem). IAC-100, CR-1, and Davis showed the smallest percentages of plants with green stem $(6.4,10.3$ and $18.3 \%$, respectively) compared to CR-3 (64.8\%) and Cristalina (77.3\%).
\end{abstract}

Index terms: Glycine max, plant resistance, soybean flavor, IAC-100, Davis, Cristalina.

\footnotetext{
${ }^{1}$ Aceito para publicação em 17 de fevereiro de 1999.

${ }^{2}$ Eng. Agr., M.Sc., Dep. de Biologia Animal, Universidade Federal de Viçosa (UFV), CEP 36571-000 Viçosa, MG.

${ }^{3}$ Eng. Florestal, Ph.D., Dep. de Biologia Animal, UFV.

${ }^{4}$ Eng. Agr., D.Sc., Dep. de Biologia Animal, UFV. E-mail: picanco@mail.ufv.br
}

\section{INTRODUÇÃO}

A soja é uma das principais culturas geradoras de divisas para o Brasil. O seu óleo é amplamente aceito pelo consumidor; entretanto, sua fração protéica e seus derivados têm pouca aceitação. Tal 
fato advém do sabor da leguminosa, devido à enzima lipoxigenase (Hajika et al., 1992). A Universidade Federal de Viçosa (UFV) vem conduzindo programa de melhoramento genético com vistas a obter cultivares de soja que não apresentem sabor desagradável, tornando-se possível melhor aproveitamento na alimentação humana. A exploração econômica da cultura da soja é prejudicada por problemas fitossanitários, como os insetos-praga, destacando-se os percevejos (Heteroptera: Pentatomidae), considerados as pragas-chave da cultura no Brasil. Os percevejos podem reduzir a produtividade, a qualidade das sementes, a germinação, a emergência das plântulas, e retardar a senescência das plantas (Daugherty et al., 1964; Galileo \& Heinrichs, 1978; Link \& Storck, 1978; Rossetto et al., 1984, 1995; Fernandes et al., 1994; Gazzoni, 1995; Panizzi \& Hirose, 1995).

Miranda et al. (1979), Rossetto et al. (1986, 1995) e Souza \& Toledo (1995) enfatizaram o uso de cultivares resistentes de soja como o método ideal de controle de percevejos. Entretanto, o melhoramento genético, dirigido para a produção e para a qualidade das plantas, ou de seus derivados, pode modificar os mecanismos de resistência, tornando as plantas mais vulneráveis a insetos-praga. Por isto, é importante testar novas cultivares oriundas do melhoramento genético ao ataque de pragas antes de liberarem aos agricultores.

Apesar da importância de tal fato, poucos trabalhos têm sido desenvolvidos nesta linha de pesquisa. Este trabalho objetivou estudar a resistência de duas linhagens de soja, do programa de melhoramento do sabor da Universidade Federal de Viçosa, MG, cultivadas sob dois níveis de infestação de percevejos, em comparação com três cultivares de soja.

\section{MATERIAL E MÉTODOS}

O trabalho foi conduzido no Campus da Universidade Federal de Viçosa (UFV). Os tratamentos foram os genótipos de soja CR-1, CR-3, Cristalina, Davis e IAC-100. As linhagens CR-1 e CR-3 são do programa de melhoramento do sabor da soja da UFV, sendo obtidas por retrocruzamento Cristalina x PI 408251 e Cristalina $x$ PI 205085, respectivamente. As cultivares Davis e IAC-100 foram utilizadas como padrões de suscetibilidade e de resistência a percevejos respectivamente (Panizzi et al., 1981), enquanto a cultivar Cristalina foi utilizada por ser a linhagem paterna da CR-1 e CR-3.

Para realização deste estudo, foram instalados dois experimentos. Em ambos, a adubação foi de $100 \mathrm{~kg}$ de $\mathrm{P}_{2} \mathrm{O}_{5}$ e $60 \mathrm{~kg}$ de $\mathrm{K}_{2} \mathrm{O}$ por hectare, na forma de superfosfato simples e cloreto de potássio, respectivamente. O primeiro foi instalado em 13/12/90 utilizando-se delineamento em blocos casualizados, com seis repetições. A parcela experimental foi constituída por nove fileiras de soja espaçadas de $0,5 \mathrm{~m}$, possuindo cada uma 25 plantas $/ \mathrm{m}$ linear, espaçadas de $1 \mathrm{~m}$ das adjacentes. A área útil da parcela foi formada pelas três fileiras centrais e a bordadura pelas três fileiras mais externas de cada lateral da parcela. Neste experimento, a infestação das plantas foi cerca de 2,80 percevejos/pano de batida, obtidos através de infestação natural.

O segundo experimento foi plantado em 19/12/90, utilizando-se delineamento em quadrado latino 5 x 5 . A área útil da parcela foi constituída por nove covas, em espaçamento $0,15 \times 0,15 \mathrm{~m}$, contendo cada uma, duas plantas. A bordadura das parcelas foi semelhante à do primeiro experimento, e as parcelas foram espaçadas $0,5 \mathrm{~m}$ das adjacentes. Neste experimento utilizou-se alta infestação, cuja densidade populacional foi cerca de 6,42 percevejos/pano de batida. Esta infestação foi obtida com a infestação natural existente, mais a liberação de cerca de 2 percevejos/área de cada pano de batida.

Foram colhidas 25 plantas de cada parcela para classificação da qualidade visual das sementes, empregando-se a escala utilizada por Miranda et al. (1979), em que as sementes são classificadas em: tipo 1 (sementes normais), tipo 2 (sementes com puncturas e possuindo até leve deformação) e tipo 3 (sementes com puncturas e muito deformadas). Quando atingiram o estádio $\mathrm{R}_{8,0}$, avaliaram-se a percentagem de plantas com caule verde e o grau de retenção foliar (Lourenção et al., 1987).

Posteriormente, os dados experimentais foram submetidos à análise de variância e ao teste de Tukey a $\mathrm{P}<0,05$.

\section{RESULTADOS E DISCUSSÃO}

$\mathrm{Na}$ amostragem da área experimental foram encontradas cinco espécies de percevejos: Nezara viridula (L., 1758), Piezodorus guildinii (Westwood, 1837), Acrosternum sp., Euchistus heros (Fabr., 1794) e Edessa meditabunda (Fabr., 1794). Dos espécimes liberados no experimento 2 (alta infestação), observou-se a seguinte proporção: $N$. viridula, 83,25\%; P. guildinii, 11,30\%; Acrosternum sp., 
3,48\%; E. heros, $1,10 \%$; e E. meditabunda, $0,87 \%$.

No experimento em que existia baixa infestação de percevejos (2,8 percevejos/pano de batida) não se detectaram diferenças significativas $(\mathrm{P}<0,05)$ entre os genótipos CR-1, CR-3, Davis e Cristalina $(57 \%)$ em relação à qualidade visual das sementes. Somente a cultivar IAC-100 $(76,80 \%)$ produziu sementes com qualidade visual superior (Fig. 1).

Já no experimento em que existia alta infestação de percevejos (6,42 percevejos/pano de batida), a cultivar IAC-100 apresentou porcentagem de sementes do tipo 1 superior à da cultivar Davis, e esta, por sua vez, apresentou sementes de melhor qualidade que a cultivar Cristalina e as linhagens CR-1 e CR-3 (Fig. 1).
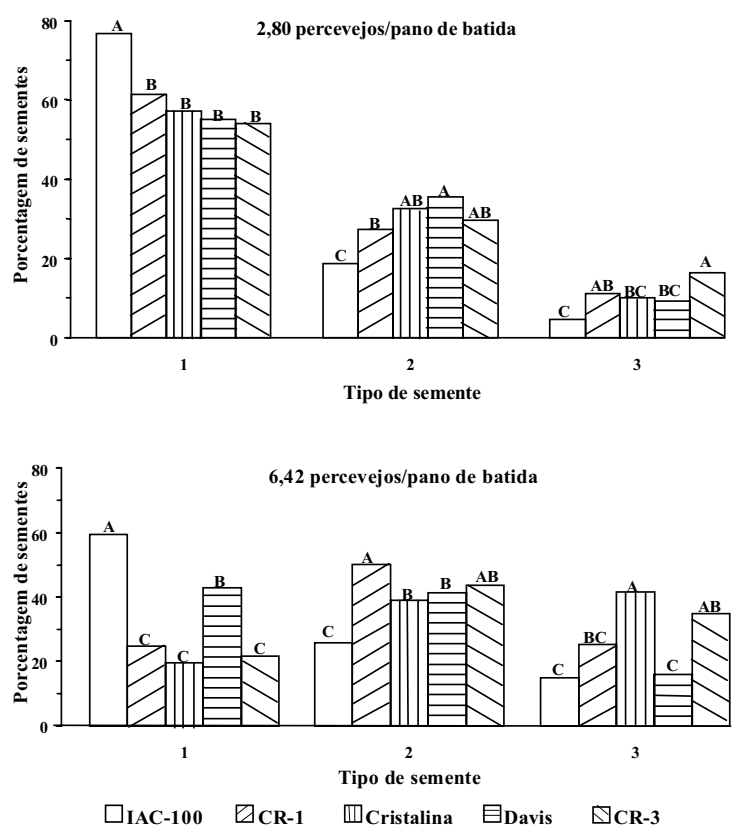

FIG. 1. Porcentagens de sementes dos tipo 1 (sementes normais), 2 (sementes com puncturas e possuindo até leve deformação) e 3 (sementes com puncturas e muito deformadas) em cinco genótipos de soja, em dois níveis de infestação de percevejos. Viçosa, MG, 1990/91. (Médias correspondentes às barras com a mesma letra, em cada tipo de semente, não diferem entre si, pelo teste de Tukey a $\mathbf{P}<0,05$ ).
A melhor qualidade das sementes das cultivares IAC e Davis do que da cultivar Cristalina e das linhagens CR-1 e CR-3, no experimento em que existia maior infestação de percevejos, deve-se à maior quantidade de lesões causadas por esses insetos-praga nos três últimos genótipos. Tal fato pode estar associado à preferência alimentar desses percevejos pelos três últimos genótipos. Em programa de melhoramento genético, dirigido à produção e à qualidade dessas plantas, ou de seus derivados, certamente comprometem e reduzem a resistência, tornando as plantas mais vulneráveis (Paschoal, 1988).

Os genótipos cultivados sob alta infestação de percevejos apresentaram níveis mais elevados de retenção de pecíolos e folhas do que quando cultivados sob baixa infestação de percevejos. Sob baixa infestação de percevejos não foram observadas diferenças significativas entre os genótipos quanto ao grau de retenção foliar (Fig. 2). A cultivar Crista-
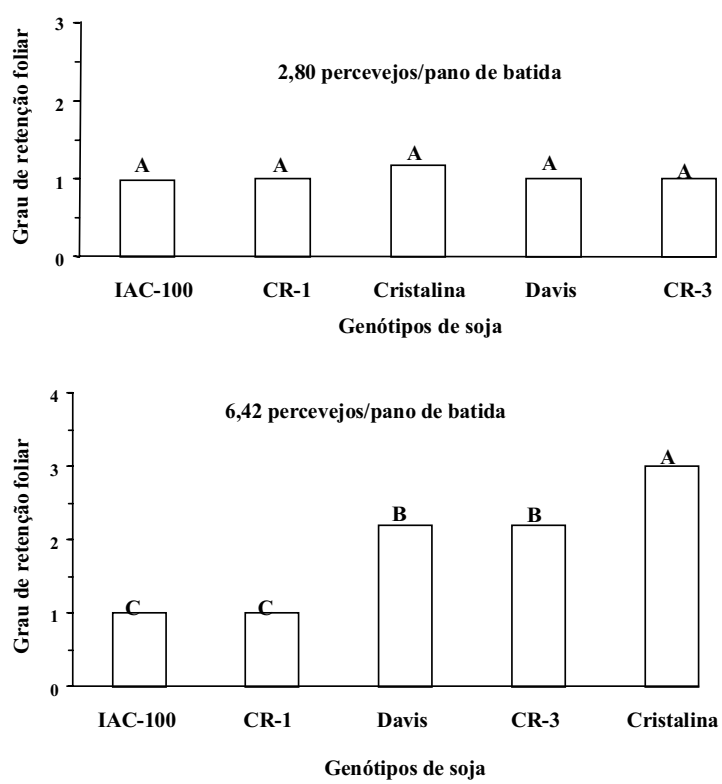

FIG. 2. Retenção foliar em cinco genótipos de soja, em dois níveis de infestação de percevejos. Viçosa, MG, 1990/91. (Grau de retenção foliar: $1=0$ a $5 \% ; 2=6$ a $20 \% ; 3=21$ a $40 \% ; 4=41$ a $60 \% ; 5=61$ a $100 \%$ ). (Médias correspondentes às barras com a mesma letra, em cada genótipo, não diferem entre si, pelo teste de Tukey a $\mathbf{P}<0,05$ ).

Pesq. agropec. bras., Brasília, v.34, n.8, p.1347-1351, ago. 1999 
lina apresentou maior grau de retenção foliar (entre $21 \%$ e $40 \%$ ), seguida por CR-3 e Davis (entre 6\% e $20 \%$ ) e CR-1 e IAC-100 (menos que 5\%) sob alta infestação (Fig. 2). Rossetto et al. (1984, 1995) e Panizzi \& Hirose (1995) relataram que, sob determinadas condições, os percevejos causam o retardamento da senescência das plantas, fenômeno conhecido como "soja louca".

Somente a cultivar Cristalina e a linhagem CR-3 apresentaram plantas com caule verde sob baixa infestação, respectivamente de $11,18 \%$ e $3,55 \%$ (Tabela 1). Sob alta infestação, a IAC-100, CR-1 e Davis apresentaram as menores porcentagens de plantas com caule verde $(10,31,18,31$ e $21,74 \%$, respectivamente), seguidas por CR-3 (64,78\%) e Cristalina (77,30\%) (Tabela 1). O fato de Cristalina dar origem a uma linhagem suscetível quase tanto como ela mesma, a CR-3, e uma linhagem resistente a percevejo, a CR-1, demonstra que a resistência ou suscetibilidade a percevejos poderá ser uma característica de herança simples, governada por poucos genes, que pode ser facilmente transferida para plantas descendentes e que não está ligada a outras características agronômicas indesejáveis, podendo ser utilizada no melhoramento da soja (Rossetto et al., 1981; Souza \& Toledo, 1995). Essa resistência, dependendo do genótipo, pode ser não-preferência alimentar, tolerância e antibiose (Jones \& Sullivan, 1979; Rossetto et al., 1981, 1984, 1995; Gilman et al., 1982). As folhas de soja, além da resistência conferida pelo efeito físico dos pêlos, são

TABELA 1. Porcentagem de plantas com caule verde em cinco genótipos de soja, em dois níveis de infestação de percevejos. Viçosa, MG, 1990/91.

\begin{tabular}{lcc}
\hline Genótipo & \multicolumn{2}{c}{ Planta com caule verde $(\%)^{1}$} \\
\cline { 2 - 3 } & $\begin{array}{c}2,80 \text { percevejos/pano } \\
\text { de batida }\end{array}$ & $\begin{array}{c}6,42 \text { percevejos/pano } \\
\text { de batida }\end{array}$ \\
\hline IAC 100 & $0,00 \mathrm{c}$ & $10,31 \mathrm{~b}$ \\
CR-1 & $0,00 \mathrm{c}$ & $18,31 \mathrm{~b}$ \\
Davis & $0,00 \mathrm{c}$ & $21,74 \mathrm{~b}$ \\
CR-3 & $3,55 \mathrm{~b}$ & $64,78 \mathrm{a}$ \\
Cristalina & $11,18 \mathrm{a}$ & $77,30 \mathrm{a}$ \\
\hline
\end{tabular}

${ }^{1}$ Médias seguidas de letras iguais, na mesma coluna, não diferem entre si, pelo teste de Tukey a $\mathrm{P}<0,05$.

Pesq. agropec. bras., Brasília, v.34, n.8, p.1347-1351, ago. 1999 ricas em alomônios que afetam o metabolismo e comportamento de fitófagos. Saponinas e inibidores de proteases são algumas das substâncias presentes em sementes de soja que inibem o ataque de pragas (Sirisingh \& Kogan, 1982).

A linhagem CR-1 é viável para a produção de grãos, pois, apesar de o seu desempenho ter sido inferior ao do genótipo IAC-100 na produção de sementes tipo 1, a CR-1 apresentou a maior porcentagem de sementes do tipo 2, além de resultados semelhantes à IAC-100 quanto ao grau de retenção foliar e percentagem de plantas com caule verde sob alta infestação (6,42 percevejos/pano de batida), lembrando-se que o nível de controle para produção de grãos é de 4,0 percevejos/pano de batida no Brasil.

\section{CONCLUSÕES}

1. Sob baixa infestação de percevejos, os genótipos de soja apresentam semelhante grau de suscetibilidade aos danos causados por esses insetos-praga.

2. Sob alta infestação de percevejos, a linhagem CR-1 e a cultivar IAC-100 são os genótipos de soja com menor suscetibilidade aos danos causados por esses insetos-praga, enquanto a cultivar Cristalina é a mais suscetível; a cultivar Davis e a linhagem CR-3 apresentam mediana suscetibilidade a esses insetos-praga.

\section{REFERÊNCIAS}

DAUGHERTY, D.M.; NEUSTADT, M.H.; GEHRKE, C.W.; CAVANAH, L.E.; WILLIAMS, L.F.; GREEN, D.E. An evaluation of damage of soybeans by brown and green stink bugs. Journal Economic of Entomology, College Park, v.57, n.5, p.719-722, 1964.

FERNANDES, F.M.; ATHAYDE, M.L.F.; LARA, F.M. Comportamento de cultivares de soja no campo em relação ao ataque de percevejos. Pesquisa Agropecuária Brasileira, Brasília, v.29, n.3, p.363-367, 1994.

GALILEO, M.H.; HEINRICHS, E.A. Retenção foliar em plantas de soja (Glycine max (L.) Merrill), resultante da ação de Piezodorus guildinii (Westwood, 1837) (Hemiptera: Pentatomidae) em diferentes níveis e 
épocas de infestação. Anais da Sociedade Entomológica do Brasil, Jaboticabal, v.7, n.2, p.85-98, 1978.

GAZZONI, D.L. Efeito associado de cultivar e inseticida no controle de percevejos (Heteroptera: Pentatomidae) que atacam a soja. Anais da Sociedade Entomológica do Brasil, Londrina, v.22, n.1, p.105-114, 1995.

GILMAN, D.F.; McPHERSON, R.M.; NEWSOM, L.D.; HERZOG, D.C.; WILLIAMS, C. Resistance in soybeans to the southern green stink bug. Crop Science, Madison, v.22, n.3, p.573-576, 1982.

HAJIKA, M.; KITAMURA, K.; IGITA, K.; NAKAZAWA, Y. Genetic relationships among the genes for lipoxygenase-1, -2 and -3 isozymes in soybean [Glycine max (L.) Merrill] seed. Japanese Journal of Breeding, Tokio, v.42, n.4, p.787-792, 1992.

LINK, D.; STORCK, L. Correlação entre danos causados por pentatomídeos, acamamento e retenção foliar em soja. Revista do Centro de Ciências Rurais, Santa Maria, v.8, n.4, p.297-301, 1978.

LOURENÇÃO, A.L.; MIRANDA, M.A.C.; NAGAI, V. Resistência de soja a insetos: VII. Avaliação de danos de percevejos em cultivares e linhagens. Bragantia, Campinas, v.46, n.1, p.45-57, 1987.

MIRANDA, M.A.C.; ROSSETTO, C.J.; ROSSETTO, D.; BRAGA, N.R.; MASCARENHAS, H.A.A.; MASSARIOL, A. Resistência de soja a Nezara viridula (L.) e Piezodorus guildinii (Westw.) em condições de campo. Bragantia, Campinas, v.38, n.19, p.181-188, 1979 .

JONES, W.A.; SULLIVAN, M.J. Soybean resistance to the southern green stink bug, Nezara viridula. Journal Economic of Entomology, College Park, v.72, n.4, p.628-632, 1979.

PANIZZI, A.R.; BAYS, I.A.; KIIHL, R.A.S.; PORTO, M.P. Identificação de genótipos fontes de resistência a percevejos-pragas da soja. Pesquisa Agropecuária Brasileira, Brasília, v.16, n.1, p.33-37, jan. 1981.
PANIZZI, A.R.; HIROSE, E. Survival, reproduction, and starvation resistance of adult southern green stink bug (Heteroptera: Pentatomidae) reared on sesame or soybean. Annals of the Entomological Society of America, Lanham, v.88, n.5, p.661-665, 1995.

PASCHOAL, A.D. Pragas da agricultura nos trópicos. Brasília: ABEAS, 1988. 72p. (módulo 3.1).

ROSSETTO, C.J.; GALLO, P.B.; RAZERA, L.F.; BORTOLETTO, N.; IGHE, T.; MEDINA, P.F.; TISSELLI-FILHO, O.; AQUILERA, V.; VEIGA, R.F.A.; PINHEIRO, J.B. Mechanisms of resistance to stink bug complex in the soybean cultivar IAC-100. Anais da Sociedade Entomológica do Brasil, Londrina, v.24, n.3, p.517-522, 1995.

ROSSETTO, C.J.; IGUE, T.; MIRANDA, M.A.C.; LOURENÇÃO, A.L. Resistência de soja a insetos: VI. Comportamento de genótipos em relação a percevejos. Bragantia, Campinas, v.45, n.2, p.323-325, 1986.

ROSSETTO, C.J.; LOURENÇÃO, A.L.; IGUE, T.; MIRANDA, M.A.C. Picadas de alimentação de Nezara viridula em cultivares e linhagens de soja de diferentes graus de suscetibilidade. Bragantia, Campinas, v.40, n.10, p.109-114, 1981.

ROSSETTO, C.J.; LOURENÇÃO, A.L.; MIRANDA, M.A.C.; IGUE, T. Resistência de soja a insetos. II. Teste de livre escolha entre a linhagem IAC-73/228 e o cultivar Paraná infestadas por Nezara viridula (L.) em telado. Bragantia, Campinas, v.43, n.1, p.141-153, 1984.

SIRISINGH, S.; KOGAN, M. Insects affecting soybeans in storage. In: SINCLAIR, J.B.; JACKOBS, J.A. (Eds.). Soybean seed quality and stand establishment. Proceedings of a Conference for Scientists of Asia. Urbana-Champaign: University of Illinois, College of Agriculture, 1982. p.77-82. (INTSOY Series)

SOUZA, R.F. de; TOLEDO, J.F.F. de. Genetic analysis of soybean resistance to stink bug. Revista Brasileira de Genética, São Paulo, v.18, n.4, p.593-598, 1995. 